\title{
Hemorragia alveolar associada a nefrite lúpica*
}

\section{Alveolar hemorrhage associated with lupus nephritis}

\author{
Ricardo henrique de Oliveira Braga Teixeira ${ }^{1}$, Marcel hiratsuka ${ }^{2}$, \\ Flávia Calderini Rosa ${ }^{2}$, Rogério Souza ${ }^{3}$, Carlos Roberto Ribeiro de Carvalho ${ }^{4}$ (te sbPt)
}

Hemorragia alveolar, como causa de insuficiência respiratória, é pouco freqüente, com diversas etiologias possíveis. Entre elas, o lúpus eritematoso sistêmico, que se apresenta geralmente como síndrome pulmão-rim, possui alta morbimortalidade. Acredita-se que a patogênese da microangiopatia, tanto renal como pulmonar, esteja associada ao depósito de imunocomplexos, que ativariam as vias de apoptose celular. Relatam-se dois casos de pacientes com nefrite lúpica que evoluíram com hemorragia alveolar associada à insuficiência respiratória necessitando de ventilação mecânica com evoluções totalmente distintas frente às terapias farmacológicas. 0 achado de anticorpos antimembrana basal em um dos casos evidencia a multiplicidade de mecanismos fisiopatológicos possivelmente envolvidos, que poderiam justificar as respostas heterogêneas frente aos tratamentos disponíveis. (J Pneumol 2003;29(6):401-4)

Descritores - Lúpus eritematoso sistêmico/ etiologia. Nefrite lúpica/ etiologia. Insuficiência respiratória/ complicações.

\section{INTRODUÇÃO}

H emorragia alveolar difusa é uma causa pouco freqüente de insuficiência respiratória. Ela pode ter diversas etiologias possíveis, tais como: infecções, toxinas inaladas, distúrbios de coagulação, síndrome de Goodpasture, poliangeíte microscópica, granulomatose de Wegener, e colagenoses, como a esclerodermia e o lúpus eritematoso sistêmico (LES). ${ }^{(1,2)}$

A concomitância de hemorragia alveolar e glomerulonefrite constitui a síndrome pulmão-rim, freqüentemente
Alveolar hemorrhage leading to respiratory failure is uncommon. Various etiologies have been reported, including systemic lupus erythematosus, which generally presents as pulmonary-renal syndrome. It is believed that the pathogenesis of microangiopathy is related to deposits of immune complexes that lead to activation of cellular apoptosis. The authors report two cases of alveolar hemorrhage and respiratory failure, both requiring mechanical ventilation. The two cases had opposite outcomes after pharmacological therapy. The presence of anti-glomerular basement membrane antibodies in one of the cases demonstrates the multiplicity of physiopathological mechanisms that may be involved. This multiplicity of mechanisms provides a possible explanation for the heterogeneous responses to the available treatments.

Key words - Lupus erythematosus systemic/ etiology. Lupus nephritis/ etiology. Respiratory insufficiency/ complications.

Siglas e abreviaturas utilizadas neste trabal ho

GBM - Membrana basal glomerular

LES - Lúpus eritematoso sistêmico

PEEP - Pressão expiratória final positiva

UTI - Unidade de terapia intensiva

associada à presença de anticorpos anticitoplasma de neutrófilos ou de antimembrana basal do glomérulo (antiGBM). 0 tipo de injúria, alveolar e/ ou glomerular, determina a evolução e o prognóstico dessa síndrome. ${ }^{(1)}$
* Trabalho realizado na Disciplina de Pneumologia - UTI Respiratória, Faculdade de Medicina da Universidade de São Paulo, SP.

1. Médico Preceptor.

2. Médico Residente de Clínica Médica.

3. M édico Assistente Doutor Responsável pelo Grupo de Hipertensão Pulmonar (TE SBPT).
4. Professor Associado/ Livre-Docente Responsável pela UTI Respiratória (TE SBPT). Título de especialista pela Sociedade Brasileira de Pneumologia e Tisiologia.

Endereço para correspondência - Serviço de Pneumologia do HCFMUSP, Av. Dr. Enéas de Carvalho A guiar, 255, sala 7.079 - 05403 900 - São Paulo, SP. Tel.: (11) 3069-7202; e-mail: rgrsz@uol.com.br Recebido para publicação em 28/4/03. Aprovado, após revisão, em 31/7/03. 

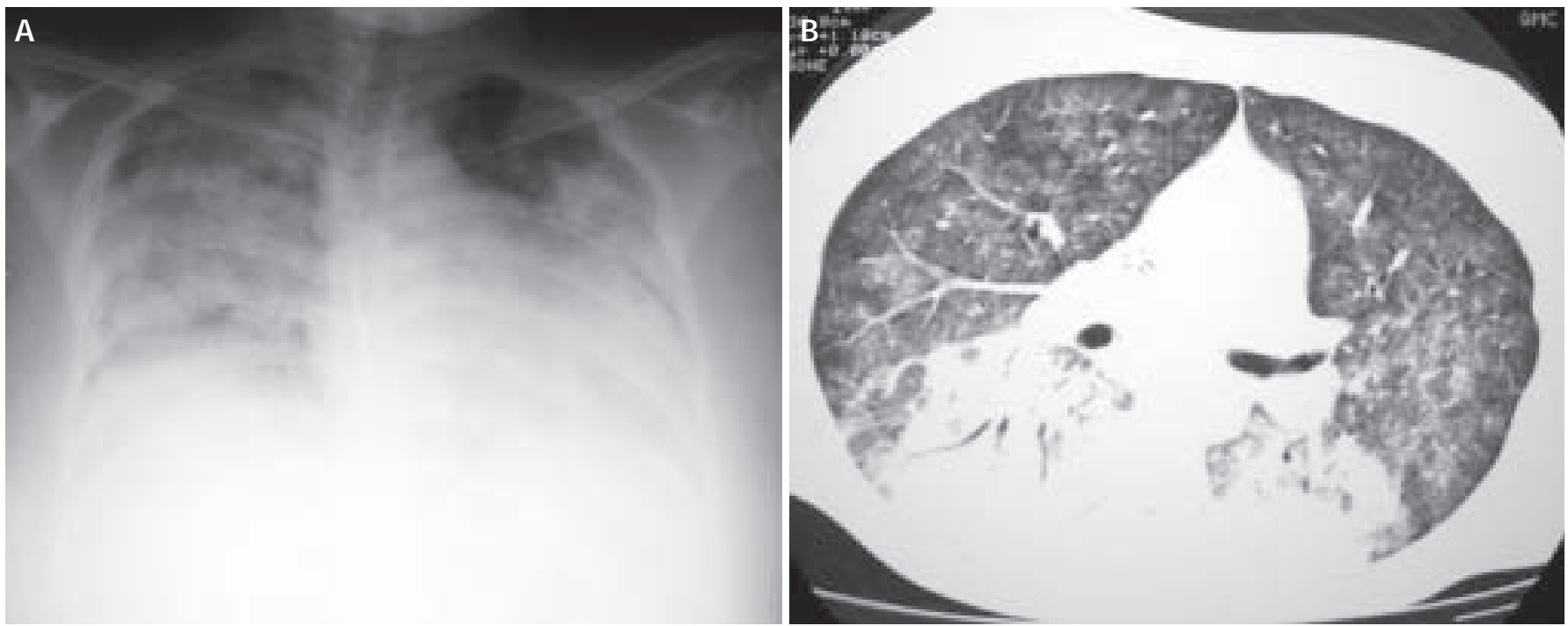

Figura 1 - Radiografia (A) e tomografia (B) de tórax do caso 1 evidenciando infiltrado alveolar difuso com áreas de condensação em ambas as bases

O diagnóstico de hemorragia alveolar é estabelecido por quadro pulmonar agudo, com hemoptise, novo infiltrado alveolar na radiografia de tórax, queda das taxas de hemoglobina e lavado broncoalveolar hemorrágico ou com macrófagos repletos de hemossiderina; não necessariamente todos os critérios devem estar presentes ao mesmo tempo. ${ }^{(1,3)}$

A presença de hemorragia alveolar difusa em pacientes com LES é uma situação rara, cerca de $2 \%$ dos casos, e freqüentemente associada a elevado índice de mortalidade. Na maioria dos casos há, ao mesmo tempo, acometimento renal. (3)

Relatamos dois casos de paciente com nefrite lúpica que evoluíram com hemorragia alveolar e foram admitidos em unidade de terapia intensiva (UTI Respiratória do H ospital das Clínicas da Faculdade de Medicina da Universidade de São Paulo), no período de junho a agosto de 2002.

\section{ReLATO dOS CASOS}

\section{Caso 1}

O primeiro caso foi o de uma mulher de 18 anos, com diagnóstico de LES havia dois anos e meio, com manifestação cutânea e articular em tratamento com cloroquina na dose de $250 \mathrm{mg} / \mathrm{dia}$.

U m mês antes da internação, suspendeu, sem orientação médica, a medicação, evoluindo com dispnéia progressiva até aos pequenos esforços, fraqueza muscular e, quatro dias antes da internação, com diminuição do débito urinário. Em decorrência da agudização do quadro de dispnéia, foi levada ao serviço de emergência.
A presentava-se com intenso desconforto respiratório, taquipnéica (30 incursões por minuto) e hipoxêmica (saturação de oxigênio de $88 \%$, em ar ambiente). Negava expectoração. A radiografia de tórax revelava, bilateralmente, infiltrado pulmonar alveolar e derrame pleural pequeno (Figura 1A). Os exames laboratoriais evidenciaram anemia, leucócitos normais, piora da função renal e provas de atividade inflamatória positivas. $\mathrm{Na}$ ausência de sinais infecciosos evidentes, fez-se a hipótese de hemorragia alveolar.

Ela foi transferida para a unidade de terapia intensiva, sendo instituída ventilação não-invasiva. Foi necessária intubação orotraqueal em virtude de piora mais acentuada. Realizou-se lavado broncoalveolar com recuperação de material hemorrágico, cujas culturas foram negativas, o que caracterizou apenas presença de hemorragia alveolar. No ajuste dos parâmetros da ventilação invasiva, utilizou-se pressão expiratória final positiva (PEEP) de até $22 \mathrm{cmH}_{2} \mathrm{O}$, com reposta parcial do ponto de vista da oxigenação. Foi realizada pulsoterapia com metilprednisolona endovenosa e mantida a cloroquina. $\mathrm{Na}$ ausência de resposta, optou-se por plasmaférese por três dias e foi iniciada imunossupressão com ciclofosfamida. Instituiuse, ainda, após novos episódios de sangramento, tratamento com gama-globulina. Nenhuma medida, entretanto, obteve sucesso para interromper os sangramentos, que recorriam a cada três a sete dias.

A função renal na internação já evidenciava aumento desproporcional da creatinina (uréia $=60 \mathrm{mg} / \mathrm{dl} /$ creatinina $=2,1 \mathrm{mg} / \mathrm{dl}$ ), a qual piorou ao longo do tratamento, mesmo com reposição volêmica e com a terapia imunossupressora já mencionada. A partir do $42 \circ$ dia de inter- 

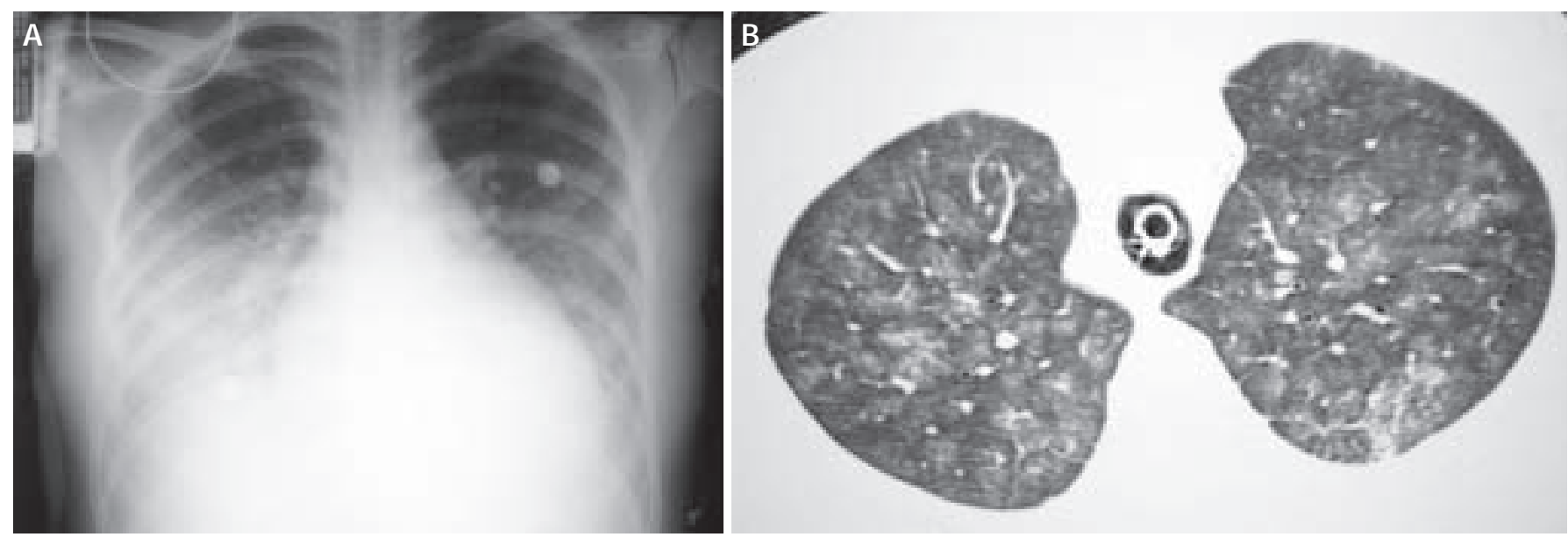

Figura 2 - Radiografia (A) e tomografia (B) de tórax do caso 2 evidenciando infiltrado alveolar difuso, bilateralmente

nação, a paciente passou a necessitar de terapia dialítica. No 61 으 dia de internação, apresentou quadro de hipertensão intracraniana e a tomografia computadorizada revelou grande área de isquemia cerebral hemisférica à direita, com intenso edema e desvio da linha média. Ela foi submetida a craniotomia descompressiva, porém evoluíu para óbito no pós-operatório imediato.

\section{Caso 2}

O segundo caso foi o de uma mulher de 40 anos, havia 17 com diagnóstico de LES, apresentando artrite de pequenas e grandes articulações, eritema malar e serosite, além de acometimento renal, com proteinúria e redução do clearance de creatinina $(40 \mathrm{~mL} / \mathrm{min})$ desde o diagnóstico. Realizou, à época, biópsia renal, que revelou glomerulopatia membranosa e mesangial.

Ela apresentou queda progressiva da função renal até havia cinco anos, quando, após pulsoterapia com ciclofosfamida, obteve melhora parcial. Havia três anos, iniciou o uso de micofenolato de mofetil.

Havia um mês dessa internação, passou a apresentar piora da função renal, evoluindo com aumento da proteinúria, hipoalbuminemia, dislipidemia, anasarca e anúria, tendo sido hospitalizada para pulsoterapia com metilprednisolona. Foi realizada, ainda, pulsoterapia com ciclofosfamida, em virtude da ausência de resposta à terapia anterior, mas também sem bons resultados. Iniciou, então, programa de hemodiálise.

A paciente evoluiu, durante a internação, com quadro de dispnéia progressiva e queda da hemoglobina, além de infiltrado alveolar à radiografia de tórax (Figura 2A). A pós episódio de intensa taquipnéia, queda da saturação arterial e hemoptise, foi transferida para a UTI. Foi submetida à intubação orotraqueal e, em seguida, foi feita broncoscopia com lavado broncoalveolar, o qual mostrou sangramento. O citológico do lavado revelou a presença de macrófagos com grânulos de hemossiderina, confirmando a hipótese de hemorragia alveolar.

Durante a internação na UTI, foi ventilada com PEEP de $18 \mathrm{cmH}_{2} \mathrm{O}$ e volume corrente de $6 \mathrm{ml} / \mathrm{kg}$, e não apresentou outros episódios de sangramento. Foi mantida em ventilação invasiva por cinco dias e apresentou rápida melhora do padrão respiratório, podendo ser extubada e mantida com máscara de nebulização de oxigênio e períodos de ventilação não-invasiva. Utilizou prednisona como monoterapia até a alta da UTI.

\section{DISCUSSÃO}

A hemorragia alveolar associada ao LES é bastante rara, acometendo apenas $2 \%$ dos pacientes lúpicos, e indica mau prognóstico, com mortalidade variando entre 70 e $90 \% .^{(1,4)}$ Os estudos histológicos pulmonares de casos relatados na literatura mostraram que, em cerca de $70 \%$ das biópsias, havia poucas alterações inflamatórias e predominância de características de hemorragia. Os demais casos mostravam alterações histológicas compatíveis com capilarite neutrofílica ou dano alveolar difuso. ${ }^{(4)}$

Em cerca de $75 \%$ dos casos de hemorragia alveolar associada ao LES, evidencia-se depósito de imunocomplexos na parede alveolar, embora a maioria dos casos seja caracterizada por achados histológicos de hemorragia com pouca inflamação (apenas $7 \%$ apresentavam capilarite neutrofílica). ${ }^{(4,5)}$

À microscopia eletrônica, observa-se depósito de imunocomplexos na parede alveolar e, nos casos associados a microangiopatia renal, depósitos na membrana capilar glomerular basal, subendotelial, característicos da nefropatia lúpica tipo IV. Na literatura, a maioria dos casos de microangiopatia renal está relacionada aos tipos III e IV 
de nefropatia lúpica. Raramente, os tipos II (mesangial) e $\mathrm{V}$ (membranoso) apresentam sinais de microangiopatia, exceto nos casos em que há progressão da atividade do LES, com piora da função renal. ${ }^{(3,4)}$

Em nossos casos, as duas pacientes apresentaram piora aguda da função renal. A fim de avaliar a presença de auto-imunidade, determinamos os títulos de anticorpo antimembrana basal (anti-GBM), o qual está relacionado à síndrome de Goodpasture e considerado um dos mais prevalentes em síndromes pulmão-rim.

A pesar de a dosagem ter sido negativa na paciente do caso 1 , devemos lembrar que esta já havia sido tratada com pulsos de corticóides, com imunossupressores e com plasmaférese, o que pode ter prejudicado a mensuração dos títulos de anti-GBM. A paciente do caso 2 , cujos valores de anti-GBM foram considerados positivos, já apresentava lesão renal diagnosticada (tipo V). Embora este não seja o tipo histológico mais característico da microangiopatia lúpica, pode haver progressão da doença para o tipo proliferativo, o que justificaria a piora da função renal desta paciente.

Entretanto, ainda não é possível identificar todos os fatores responsáveis pela lesão da hemorragia alveolar, bem como pela microangiopatia renal no LES. Também não é possível identificar quais fatores estariam relacionados às diferentes evoluções de cada paciente, principalmente quanto à resposta à terapia imunossupressora. 0 mesmo acontece em outros espectros das vasculites que acometem o pulmão. ${ }^{(6)}$

Ainda assim, o uso de estratégias protetoras durante a ventilação mecânica, com baixos volumes correntes e níveis elevados de PEEP, podem representar um aspecto fundamental no tratamento dos pacientes que evoluírem para quadros mais graves de insuficiência respiratória. Em um estudo realizado em pacientes com síndrome do desconforto respiratório que incluiu pacientes com hemorragia alveolar secundária a leptospirose e a outras vasculites pulmonares, o uso desse tipo de estratégia ventilatória levou à diminuição da mortalidade. (7)

Embora condição rara, o diagnóstico precoce e a introdução de medidas protetoras para o sistema respiratório podem, eventualmente, determinar mudanças no curso da hemorragia alveolar associada ao LES. Além disso, a melhor compreensão da sua fisiopatologia pode levar a tratamento farmacológico mais efetivo.

\section{REFERÊNCIAS}

1. Bosch X, Font J. The pulmonary-renal syndrome: a poorly understood clinicopathologic condition. Lupus 1999;8:258-62.

2. Bar J, Ehrenfeld M, Rozenman J, Perelman M, Sidi Y, Gur H. Pulmonary-renal syndrome in systemic sclerosis. Semin Arthritis Rheum 2001; 30:403-10

3. Lee JG, Joo KW, Chung WK, J ung YC, Zheung SH, Yoon $\mathrm{HJ}$, et al. Diffuse alveolar hemorrhage in lupus nephritis. Clin Nephrol 2001;55: 282-8.

4. Hughson MD, He Z, Henegar J, McMurray R. Alveolar hemorrhage and renal microangiopathy in systemic lupus erythematosus. Arch Pathol Lab Med 2001;125:475-83.

5. Specks U. Diffuse alveolar hemorrhage syndromes. Curr O pin Rheumatol 2001;13:12-7.

6. Lauque D, Cadranel J, Lazor R, Pourrat J, Ronco P, Guillevin L, et al. Microscopic polyangiitis with alveolar hemorrhage. A study of 29 cases and review of the literature. Groupe d'Etudes et de Recherche sur les Maladies "Orphelines" Pulmonaires (GERM"O"P). Medicine 2000;79: 222-33.

7. A mato MB, Barbas CS, Medeiros DM, Magaldi RB, Schettino GP, Lorenzi-Filho $G$, et al. Effect of a protective-ventilation strategy on mortality in the acute respiratory distress syndrome. N Engl J Med 1998;338: 347-54. 